\title{
EL ESPACIO NARRATIVO EN RABOS DE LAGARTIJA DE JUAN MARSÉ: DEL HOGAR NATAL AL ÚTERO MATERNO
}

\author{
Natalia ÁLVAREZ MÉNDEZ \\ Universidad de León
}

La condición de excelente narrador de Juan Marsé, escritor de formación autodidacta nacido en la Barcelona de 1933, se manifiesta desde sus inicios como autor y a lo largo de todo su quehacer artístico con obras como Encerrados en un solo juguete (1960), Esta cara de la luna (1962), Últimas tardes con Teresa (1966), La oscura historia de la prima Montse (1970), Si te dicen que caí (1973), La muchacha de las bragas de oro (1978), Un día volveré (1982), Ronda del Guinardó (1984), Teniente Bravo (1986) y El embrujo de Shanghai (1994). No obstante, es su último libro el que eclipsa nuestra atención al presentarse como una novela realista -con una gran riqueza espacial- en la que, a su vez, juegan un notable papel la fantasía y el humor. Rabos de lagartija ${ }^{1}$ muestra en su propio título reminiscencias de un juego de la infancia, aludiendo también de manera implícita al período de posguerra y la difícil supervivencia en eșa época. En esta novela, junto a la atenta mirada del autor a la realidad, sobresale la recurrencia de varios motivos ya plasmados en anteriores obras del escritor, aunque en este estudio no analizaremos esas interrelaciones existentes en el seno de su narrativa con el fin de no desviarnos de nuestro objetivo primordial, que es el de la representación del espacio de la historia?. Por tales razones, no incidiremos con demasiado énfasis en los caracteres de la estructura y la trama con la intención de poder profundizar en la significación de su dimensión espacial. No nos resistimos, sin embargo, a subrayar una serie de rasgos esenciales de la obra: el

' Marsé, J. 2000. Rubos' de lagartija. Burcelona: Areté.

${ }^{2}$ Somos conscientes de la importancia de realizar el análisis de esos motivos recurrentes y de llevar a cabo un seguimiento inicial del espacio en la totalidad de la obra de Juan Marsé. Sin embargo, esos trabajos supondrian una extensión desmesurada que le robaría demasiadas líneas al estudio del espacio en la novela Rabos de lagarija, un elemento con una gran rigueza significativa que merece una investigación exclusiva, aunque sea a costa de restringirla i una única parcela de la trama. 
alto grado de invención que existe en la novela a pesar de ciertas concomitancias autobiográficas; el modo en que el pesimismo se ve reducido gracias a la ironía y el humor intercalados entre los diálogos realistas; el lenguaje cuidado, pero sin conllevar una excesiva preocupación esteticista; y la manera perfecta en que el autor capta y mantiene la atención del lector hasta el final del libro, combinando la ambigüedad fronteriza entre lo real y lo ficticio, la verdad y la mentira, el bien y el mal, el amor y el desamor.

La novela se organiza en tomo a una serie de figuras que poseen una gran fuerza, como el narrador de la historia -un feto de pocos meses que está destinado a ser huérfano-, el inspector Galván enamorado de la pelirroja embarazada Rosa Bartra, el fantasma del padre libertario fugado y desaparecido, el piloto altivo de la RAF encarnado en una vieja fotografía de revista o el protagonista de la historia con su perro Chispa, un adolescente que sufre la continua tortura de un registro de voces en su mente. Concretamente, David padece una enfermedad del oído que provoca múltiples silbidos y ruidos, un fenómeno que en el joven genera la entrada continuada de voces y que le permite incluso hablar con los muertos y con los todavía no nacidos. Gracias a este fenómeno el chico es caracterizado como un personaje mentiroso, drásticamente desengañado a consecuencia de las circunstancias de la vida que le han impulsado a crecer demasiado deprisa y a fusionar la imaginación infantil con rasgos propios de un ser adulto, confundiendo lo real con lo ficticio y lo cierto con lo falso.

Nuestro objeto de análisis, el espacio narrativo, desarrolla en Rabos de lagarija un papel esencial en la trama novelesca, equiparable, en cuanto a función y significación, al de los propios personajes. La gran fuerza que desarrollan las figuras en el seno de la historia no alcanzaría cotas tan elevadas de no ser por los escenarios relevantes en los que éstas llevan a cabo sus vidas y sus relaciones con el mundo y con el entorno. No debemos olvidar que el espacio novelístico se plasma como un elemento esencial de la trama junto al tiempo, los personajes y los acontecimientos, pues los lugares de la historia constituyen marcos de referencia dentro de la obra a la vez que interactúan con otros componentes del relato. Además de constituir una sólida realidad textual, este componente de la organización narrativa se erige como una entidad ficcional que posee una gran complejidad. No es simplemente un soporte de la acción, ya que se convierte en un propulsor de la misma, llegando en determinadas obras contemporáneas a configurarse como un protagonista más de la historia. Así, el espacio sirve de enlace de los demás elementos narrativos y acentúa la verosimilitud de los personajes y los acontecimientos.

Ciertamente, desde su introducción en la narratio con los tópicos de cosa, el espacio experimentó diversas transformaciones que lo han conducido hacia la privilegiada posición que posee en nuestra novelística actual, 
ocupando un papel esencial en la ficción a raíz de la destacada relevancia que adquiere en los grandes relatos del siglo XX. De esta manera, las connotaciones significativas del espacio se incrementan con la introducción en las historias de ámbitos semiotizados y simbólicos, además de los representativos. Esto es posible porque desarrolla una doble función; por un lado la referencial al concretizar los hechos $y$, por otro, la simbólica al convertirse en una proyección metafórica de la psicología de los personajes o al condicionar su forma de actuar. Concretando más todavía, podemos vislumbrar una funcionalidad tripartita ${ }^{4}$ con una labor de configuración espacial en relación con la recreación discursiva del espacio en el texto; una función de ubicación o localización de los hechos; y con la representación de un ámbito espacial de actuación en el que se integran el tiempo, los acontecimientos y los personajes.

De igual modo, es necesario recordar la variedad de dimensiones que conforman la totalidad del signo espacial': el espacio del discurso o del significante, constituido por los signos del discurso textual; el del referente o del objeto espacial recreado en el texto; y el de la historia o el significado que construye un espacio con vida propia dentro de la ficción. Pues bien, en el espacio de la historia de Rabos de lagartija, la dimensión que atrae nuestro interés, nos encontramos ante significativos ámbitos que no se limitan a localizar la historia sino que desempeñan una gran labor simbólica a medida que intervienen en la trama hasta el punto de influir en ella como un protagonista más. Como hemos advertido en el enunciado del presente estudio, llama la atención la capacidad representativa de los espacios interiores -entre los que destaca el de la casa natal, el cuerpo y el útero materno-, aunque no debemos ignorar por ello la relevancia de algunas zonas de carácter externo. De tal forma, en el relato de los hechos acaecidos, localizados en la Cataluña de la posguerra, se aprecian tanto escenarios exteriores como interiores.

Inicialmente, sobresale el encuadre de la acción en un espacio urbano determinado y con un alto grado de verosimilitud en su recreación, a pesar de que, aün habiéndose inspirado en un referente real, al ser plasmado en el texto se transforma en un ámbito ficticio regido por unas coordenadas propias ${ }^{6}$. Esta ciudad construida por Marsé se muestra en el comienzo y a lo

${ }^{3}$ Entre otros autores, Wellek y Warren (1948: 165) han centrado su interés en esa capacidad metafórica de la dimensión espacial en la narrativa.

4 En relación a este proceso se proporcionan amplios detalles en el trabajo deValles Calatrava 1999.

"La problemática de la complejidad dimensional del signo espacial ha sido estudiada por escasos críticos. Véase en Camarero 1994.

- Así lo matizan en sus estudios Goodman, 1990: 144; Albaladejo, 1992: 103; Garrido Domínguez, 1993: 29-30 y 1997: 25. 
largo del desarrollo de la novela con pocos detalles, puesto que el protagonista suele vivir deambulando por un torrente de espaldas a la urbe y evita atravesarla siempre que puede, cambiando el camino de la avenida por el de las callejuelas de tierra batida y el barranco. Además, en las escasas ocasiones en las que penetra en ella la imagen que nos ofrece de ese lugar es pésima, ya que lo caracteriza con un fuerte "olor a pezuña quemada" y con "oscuros viandantes encorvados" deslizándose "por las calles como hurones" (p.294). Tan sólo al final de la narración, cuando el personaje ha alcanzado la mayoria de edad y se dedica al reportaje fotográfico, explorará con ansiedad ese ámbito buscando la verdad que reside en las calles de la ciudad. Sin embargo, esa contemplación de la realidad obtenida en la ciudad se truncarí con prontitud, pues en medio de una huelga y al ser perseguido por unos agentes, David es apresado por el entramado de hierros de un tranvía que le atropella. Con todo, hasta ese instante sus fotos logran captar los rasgos caracterizadores del espacio urbano del momento: ... pero la que yo conservo, la que hizo dias antes del tranvia espectral y encendido bajo la lluvia, rodeado por una muchedumbre stumisa y a la vez obstinada moviéndose a pie, raidas gabardinas en torvas espaldas y periódicos mojados en la cabeza, aquella folografia que él habia manipulado con un lápiz de punta fina en la soledad del cuarto de revelado, hoy sigue siendo la imagen más pertinente y turbadora de cuantas captó David, el testimonio más cabal y más veraz de lo que un dia, hace mucho tiempo, conmovió a esa ciudad.'

Pero, más que la ciudad como tal, el escenario externo que destaca con diferencia sobre el resto es el del barranco, que implicará, ante la peculiar percepción de todos los personajes, unas marcadas connotaciones simbólicas, Comenzando por el joven David, constatamos cómo ese espacio próximo a su casa se configura como un lugar notable en su vida, aunque con elementos tanto positivos como negativos. Por un lado, se plasma como el ámbito de sus escasos juegos, entre los que resalta el de cortar el rabo de las lagartijas ante la fascinación que le provoca el hecho de que sean capaces de continuar con vida durante un tiempo. Allí disfrutará de los pocos períodos en los que puede evadirse de la realidad que le ha hecho madurar a pasos agigantados. Por estos motivos le gustará pasar gran parte de su tiempo en ese lugar, que se convertirá en un espacio metáforico del marco de los juegos y los hallazgos, un escenario que recuerda en determinadas parcelas y matices al paraíso perdido de la infancia.

El barranco es, además, un ámbito en el que comparte confidencias con su amigo Paulino y en el que, en ocasiones, cree sentirse seguro frente al resto del mundo. Es como un escenario-refugio, de ahi sus continuos despla-

${ }^{7}$ Ibid. 1, 354. 
zamientos diarios desde la parte trasera de la casa al barranco y sus demoradas estancias sentado en el borde del abismo, cuando sabe que el inspector está en la casa y que, si regresa, le hará enfrentarse de nuevo a lo real. Ese carácter protector asimilado al barranco se manifiesta en variados pasajes, por ejemplo en el que expone el convencimiento de David de que ahí están seguros, pues a ese lugar nunca llegará "el hongo venenoso de la bomba atomicia ni su onda expansiva y achicharrante" (p.116). De la misma manera que, más tarde, incide en sus soliloquios mantenidos en el barranco en el rasgo positivo que caracteriza a ese lugar en el que se pueden olvidar, aunque sólo sea momentáneamente, las preocupaciones que acechan en el mundo circundante: Feliz tá, lagartija sin cola que habitas en las grietas del fondo de la nada, ese ningún lugar entre mi casa y el mundo, entre el silencio del torrente y la voz de papa."

No obstante, no sólo se asociarán elementos positivos a ese espacio, pues la carga pesimista que acompaña a ese marco escénico se hace latente a lo largo de toda la historia. Por una parte, se configura como una zona en la que las voces y los ruidos que resuenan en los oídos del adolescente se acrecientan de manera intensa. $Y$ por otra, a pesar de no ser un barranco profundo o tenebroso, a David le impresiona ese espacio al recrear su imagen pasada y creer con total convencimiento que algún día una gran inundación arrasará con todo: Cualquiera que se acerque a la casa remontando la suave loma desde la Avenida puede ver, en el fondo del barranco, el hilo de agua que parece muerta, la arcilla cuarteada, los desperdicios, alguna lagartija sin rabo y las raices secas y retorcidas como culebras; pero sólo David ve las aguas turbulentas que habian atronado y descarnado los flancos del tajo, sólo él conserva aquella resonancia espumosa que inunda sus oídos enfermos y le mantiene de pie y aterido sobre el abismo, soñando historias de huracanes y borrascas, nieblas espesas y tempestades y naufragios."

De igual modo, serí un marco en el que su intimidad parece peligrar, pues se sentirí continuamente observado en ese lugar, como si ojos que ya se hubieran ido siguieran vigilándole. Además, para acrecentar el halo de pesimismo que rodea al barranco y al torrente, el narrador relata cómo el lugar se convertirá en espacio-sepulcro al albergar, al menos en la imaginación de David, el cuerpo del perro Chispa sacrificado por insistencia del inspector. A lo que se suma que en ese espacio se encuentra también a menudo con la imagen del padre, desaparecido y probablemente muerto, que había huido por allí resbalando y rajándose el culo con un cristal. El chico está muy traumatizado por la actual ausencia de la figura paterna y por el permanente

"Ibid. 1, 308.

${ }^{9}$ Ibid. 1, 76. 
vacio anterior experimentado a causa de que su progenitor nunca lo quiso realmente. Por ello, confunde lo real con lo falso y el amor con el desamor, y cuando lo ve en ese lugar, -con la imagen de un hombre deriotado que ha perdido la guerra y que deambula como un vagabundo borracho-, le pide ansiosamente que se oculte bien para que no le descubran. Incluso, insistirá más tarde en que se vaya del torrente para que no le capturen, aunque en la respuesta del padre se observa nuevamente la carga negativa de ese espacio: ...estoy en el lugar que me corresponde, dentro de esa herida mal cerrada en la tierra, una barranca hedionda y falaz...

En suma, el barranco, tanto con sus elementos positivos como con los negativos, se erige en un lugar que marca la infancia perdida del David adolescente y desengañado, así como las vidas de la madre y del pequeño que ésta alberga en su útero. Serń un espacio arraigado en las entrañas de sus existencias que nunca podrán olvidar, pues su recuerdo debe permanecer para mantener la memoria de su vida. Se plasma, por lo tanto, como el marco en el que se asientan las raíces de la familia, el espacio original al que en una época posterior, siendo ya mayor de edad, David decide regresar para sacar fotos del torrente y poseer así un testimonio de ese ámbito primigenio: En esos desechos, en todos y cada uno de ellos, el ojo de la cámara indaga muy de cerca una identidad oculta y la distingue, la toca y la vuelve a pensar, la recrea más allá de la historia particular que pudiera sugerir su deterioro y su abandono. Fotografias del barranco, de lo poco que queda de sus arruinados flancos y de su vértigo infantil, en las que está depositado un sedimiento del tiempo, una reflexión de la luz que no es totalmente ajena a mi propio discurrir en este hueco de la almohada. No hay una sola voz de cuantas llevo registradas aqui, ni una sola palabra emborronada en estos viejos cuadernos escolares -olas interminables y simétricas parodiando una escritura ilegible de discapacitado, es lo que oigo decir- que no esté enraizada en aquel torrente desmoronado y pútrido que mi memoria preserva del olvido. Mi lápiz corre sobre el papel pautado solamente para mantener inviolado su recuerdo."

Obviando la relevancia de ese espacio externo del barranco, advertimos también en Rabos de lagarrija la incansable función significativa y simbólica de los ámbitos interiores en los que acontece la novela. Existen una serie de marcos escénicos notables, como el del cine que potencia con la atmósfera de sus salas tanto la evasión como el secreto y la confidencia. Por un lado, las imágenes de las películas proyectadas propician la huida de David hacia espacios exóticos y deslumbrantes en los que olvida los problemas cotidianos.

\footnotetext{
${ }^{10} \mathrm{lbid}$. 1, 306.

"lbid. 1, 347.
} 
Pero, por otro, genera el choque con la realidad a través de las respectivas confidencias de abusos sufridos y de problemas, asi como el contacto con la ambigüedad que marca su existencia al favorecer los tocamientos con su amigo Paulino: Los sábados en el cine Delicias, si la platea está a tope y toca sentarse detrás de la columna, puedes acabar con torticolis o con la cabeza apoyada en el hombro del vecino de butaca. No hay mal que por bien no venga, pensaria Paulino Bardolet, que alguna vez se habia excusado en el estorbo de esa columna para arrimarse al acompañante. Pero con David no le vale el truco, pues David prefiere sentarse en las primeras filas y cerca de los urinarios. ${ }^{1 ?}$

La peculiar semiotización que adquiere el espacio de la noche es la que da lugar a que, a pesar de las iniciales reticencias del joven, siempre termine manteniendo relaciones con el compañero, amparándose en la oscuridad del cine que desfigura los límites espaciales dibujados en otras ocasiones por la claridad propia del dỉa. Ese mismo marco en penumbra no sólo aporta la incertidumbre propia de la distorsión y de la desaparición de fronteras espaciales, sino que potencia el misterio en otros pasajes, como aquel en el que un hombre sin contomos y convertido en sombra le entrega en absoluto secreto un sobre dirigido a su madre.

A pesar de todo, cuando constatamos la gran capacidad expresiva y significativa de los espacios interiores nos preocupa mayormente el poder simbólico del espacio de la casa natal, el del propio cuerpo y el del útero matemo. En primer lugar, el hogar de la familia del protagonista aparece caracterizado bajo varias semiotizaciones. A menudo se hace alusión a la oposición dialéctica entre la imagen pasada y presente de la casa con su consiguiente significado y en intensa vinculación con la contraposición entre espacio rico y pobre. En esta línea se plantean las lujosas condiciones que en épocas anteriores poseía la casa, con una vistosa fachada y un humilde jardín ahora deslucido y recreado por la madre con melancolía: Más tarde ella sale por la puerta principal con la cesta de la colada en la cadera y cruza el jardín abolido, pasando entre rosales y adelfas que su nostalgia cultiva todavía en la memoria, en dirección al barranco donde David, sentado en el borde junto a Chispa, balancea los pies en el vacío y habla solo. ${ }^{13}$

La imagen que ofrece la casa en la actualidad es la de una modesta vivienda situada en lo alto de la ciudad, en un callejón sin salida y al borde de un barranco. El entomo del callejón resalta por escasas casuchas rodeadas de tierra negruzca, orines y regueros de agua sucia, donde los protagonistas viven como realquilados en la zona correspondiente a un antiguo consultorio

12 lbid. 1,88 .

Ibid. 1, 192-193. 
de otomino situado dentro de un viejo edificio con ínfulas de chalé. Sin embargo, a pesar de una serie de ausencias relevantes como la de la figura paterna y la de determinados bienes materiales para subsistir, la casa de la pelirroja albergará en su interior un verdadero hogar. El protagonismo que alcanza la figura de la vivienda es tan enorme, al abrigar la intimidad de la familia, que llega a adquirir existencia en cada sueño o recuerdo de los personajes. De ahí la importancia esencial que ese lugar posee para el narrador que sólo vivió en él a través de su percepción como feto, pero cuyo recuerdo permanece en su mente con el paso de los años marcando su existencia: Rojas y ásperas, las manos de mamá remueven retales de colores en una caja de cartón y David retiene los aromas. Alinidón y lejía y sosa y una luz algodonosa en los cristales de la ventana. La casa que nunca habité es más real y tangible que este mordisqueado lápiz mío que traza garabatos sobre el papel. ${ }^{14}$

Ese carácter de hogar natal influyente en la conciencia de los personajes, que será recordado de por vida como un espacio protector incomparable a todos los demús, es conseguido gracias al espíritu luchador e imbatible de la pelirroja. Esa mujer emigrante, de padres canarios y procedente de Andalucía, tras veinte años de residencia en Cataluña teme que cualquier día el procurador les eche a la calle a causa de la muerte de la dueña. No obstante, limita su hogar al consultorio realquilado y sólo entra en el resto de la vivienda para acondicionarla y limpiarla a fin de que no sea invadida por las ratas. La casa es un espacio de la intimidad en el que, por muy pobre o lujoso que sea, lo importante es la sensación que genera en el ser humano que la habita. Así, en sus reducidos lindes, Rosa Bartra construye un simple pero no frágil nido"s, un verdadero hogar, haciendo caso omiso de las incomodidades y de la pobreza que envuelve el ambiente: La minúscula vivienda de realquilados está vista en un santiamén. Apenas cincuenta metros cuadrados. No hay recibidor ni vestíbulo ni antesala de nada: al cruzar el umbral ya se halla uno en el comedor, asi de sopetón, frente a una mesa rectangular cubierta con un hule a cuadros, a un lado el aparador y al otro, bajo la ventana con celosías que da al callejón visto en profundidad, la máquina de coser Nogma, la mesa camilla y dos sillones de mimbre. Se ve muy claro que lo que hoy es recibidor, comedor y sala de estar, todo a la vez, antes era salita de espera del consultorio médico: en la pared aín hay manchas descoloridas y clavos donde colgaban cttadros y diplomas. ${ }^{\text {th }}$

1 Ibid. 1, 16-17.

${ }^{15}$ En relación con el simbolismo del espacio de la casa como imagen de un nido en el mundo frente a la hostilidad del exterior, vénse el estudio de Gaston Bachelard 1965: 137.

${ }^{16}$ Ibid. 1, 51 . 
La pobreza inunda, por lo tanto, todas las estancias de tamaño mínimo como el dormitorio de la madre en el que trabaja las telas y que antes era el lugar en el que el otorrino trataba a sus pacientes. $O$ el cuchitril que hace las veces de cuarto de David, -anteriormente el almacén de específicos e instrumental médico-, que consta de un pequeño ventanuco alto y de múltiples desconchados provocados por la humedad. Pero ante la escasez de recursos, Rosa Bartra adoma las puertas con cortinas y visillos, coloca fotos del marido y del hijo mayor muerto $y$, pese a la ausencia de lujos, proporciona a ese ámbito otro aspecto con su serenidad, su firmeza, su coraje y sus ansias por construir un verdadero hogar y por combatir las mil caras bajo las que se presenta la pobreza cotidiana. De tal modo, no sólo interesa la influencia que la casa provoca en sus habitantes sino también la que estos imprimen a ese espacio: ...que a pesar de la limpieza y el orden que ella impone a su alrededor con la mayor presteza y energía, las cosas nunca parecen esiar en su sitio, andan siempre por ahf ocupando con una porfía insidiosa el lugar que un día correspondió a otras. $Y$ sin embargo, en medio de su aparente extravio, asi dispuestos en su mundo de precarias apariencias, ninguno de esos objetos ha sido despojado de su identidad, al contrario, parecen más próximos y necesarios y su trato más cordial. ${ }^{17}$

Al margen de los aspectos ya citados el hogar manifiesta, además, una mayor variedad expresiva y significativa que alcanza los límites de lo simbólico. Este fenómeno se debe a la existencia, muy remarcada a lo largo de la historia, de dos puertas en la casa, por un lado la que se abre hacia el callejón y al día y, por otro, la que se abre al barranco y a la noche. Según David, la primera servirá para ocultarse en casa de día y la segunda para escapar por la noche. Cumplen, pues, dos funciones distintas pero complementarias, al ser utilizadas siempre para resguardarse de la realidad circundante y al estar en intensa relación con la semiotización del espacio del día y de la noche.

Al protagonista, la puerta del día le servirá para huir y ocultarse del mundo aprovechando la intimidad otorgada en el seno del hogar para actuar a su antojo y disfrazarse de chica. En el dormitorio del muchacho los propios objetos $^{11}$ del adolescente - una sobada novela de Edgar Wallace, un cortaplumas nacarado, un rabo de lagartija reseco, un reloj de pulsera de tela y con las manecillas pintadas- nos revelan la contradictoria personalidad del muchacho asediado por la ambiguiedad y el desengaño ante el mundo que le rodea,

I /bid. 1, 175-176.

u Es fundamental dirigir también la atención a los objetos propios de la casa que reflejan aspectos claves de la intimidad de un personaje y pueden contribuir, por lo tanto, a esclarecer las connotaciones psicológicas que se desprenden de esa espacialidad ficcional. 
del que no podrá evadirse permanentemente ni siquiera con la imaginación. Por ello, aunque el marco interior de la casa parezca proporcionarle refugio y protección frente al exterior, en ciertos casos se transformará en un lugar opresor, volviéndose muy hostil en ocasiones en las que, por ejemplo, se ve atormentado por los ruidos y las voces que atronan sus oídos en el silencio del cuarto. El mismo proceso acontece cuando se sobresalta de madrugada al temer la presencia oculta del inspector en la negrura del armario ropero entreabierto ${ }^{19}$, o cuando sospecha ser espiado, como se manifiesta en la conversación con el fantasma de su perro: Las paredes oyen, susurra el animal mirando el remolino central de la oreja del otorrino con el rabillo del ojo apesadumbrado, como si temiera ser absorbido por el gran apéndice de un momento a otro. ${ }^{20}$

Por estos motivos se produce el trayecto contrario al de la inicial huida desde la realidad del callejón hacia la seguridad de la casa, pues, cuando el espacio del hogar se vuelve hostil u opresor, el chico escapa hacia el callejón por la puerta del día. Así ocurre cuando saca a Chispa para que se sienta "menos solo y quebrantado" (p.38). Con un carácter igual de fronterizo y contradictorio se recrea la puerta de la noche, la que conduce hacia el barranco tan determinante en la vida de David y la que es definida por el policía como una zona de escape y de olvido: El inspector sale hasta el borde del barranco: "decididamente Víctor Bartra escapó por aquit, ésa es la puerta de la noche, el umbral del abismo y del olvido, el desagüe de un pasado criminal...21 Lamentablemente, para alcanzar esa puerta de la noche y olvidar momentáneamente la realidad, David debe enfrentarse a un espacio caracterizado negativamente, el lado oscuro y deshabilado de la casa que, aunque en continuidad con él, no corresponde al hogar situado en el antiguo consultorio. En esa zona los muebles crujen y las paredes se desconchan, se deterioran las cortinas y los espejos, la atmósfera se le antoja fantasmal a causa de la penumbra y de las connotaciones fúnebres de los muebles pudriéndose amortajados en fundas amarillas. Es un ámbito cerrado, con olor a difunto y a apolillado, un lugar que recuerda la muerte a través de la imagen del abandono, pues el objeto que no es posé́do por alguien deja de existir: Todo lo que David ve en este salón, siempre que tiene que cruzarlo solo, yendo o vi-

${ }^{10}$ Los armarios aparecen en la narrativa como espacios de la intimidad en los que se ocultan o guardan parcelas de la propia psicología de un personaje, plasmándose como una memoria de recuerdos. Sin embargo, en este episodio de Rabos de lagartija se muestra como un ámbito hostỉ que se aproxima a las connotaciones significativas de oscuridad y temor propias de espacios subterráneos o sótanos.

${ }^{20}$ lbid. $1,255$.

"lbid. 1, 63. 
niendo del baño o de la cocina, ya no parece vivir en el tiempo, solamente en la memoria desbaratada de alguien; muebles renqueantes y desplazados, cortinas tiesas y visillos desflecados, grandes cuadros torcidos en la pared. anticuados y sombrios, con liebres y perdices muertas expuestas sobre mesas repletas de verduras y frutas, todo parece no sólo haber sido abandonado hace muchos años con premura y sin el menor afecto por quienes vivieron aqui, sino haber sido repudiado y maldecido, entregado rabiosamente a una voluniaria desmemoria. 22

Esta doble entrada de la casa también pone de relieve otro aspecto espacial fundamental, el que muestra la imagen del hogar como una fortaleza para sus habitantes, un ámbito privado sobre el que ellos tienen el poder. Así se plasma durante todos los dias en los que el inspector Galván, el policía encargado de investigar la huida del padre del protagonista, no consigue acceder al interior de la vivienda al encontrarse-obligado ante la privacidad que sugiere ese ámbito- relegado a la entrada exterior del lugar. Por tal causa, ante el espacio fronterizo de la puerta principal de la casa, la del día, el inspector se situará frente a ella continuamente en el callejón, marco en el que deberá interrogar a David y a su madre. No debemos olvidar la categoría de espacio-límite de la puerta en nuestra narrativa que, de manera paralela y quizá contradictoria, une y separa varios lugares. En Rabos de lagartija las puertas externas de la casa servirún para unirla con el exterior en ciertas ocasiones y, en otras, para aislarla del mundo y del entorno inmediato.

Por todos los aspectos mencionados no debe extrañamos que al comienzo de la historia se observe la hostilidad con que la pelirroja recibe a Galván en el hecho de sujetar las puertas sin la menor intención de permitirle el paso. Incluso, en la primera ocasión en la que el hombre consigue entrar lo logra haciendo uso de su autoridad y justificando la necesidad de registrar el chalé por el bien de su investigación. Pero las cosas cambiarán a medida que transcurre la acción, pues el policía cada vez coge mayor confianza con la madre de David, a la que el chico no quiere ver a solas con ese hombre en la casa. A pesar de ello, se produce un acercamiento inicial en el lado de la puerta de la noche, en una pequeña explanada entre la casa y el barranco. A raiz de ese encuentro el inspector regresará, cada vez con mayor asiduidad, con el deseo de poder franquear el límite espacial impuesto por la privacidad de la puerta que salvaguarda la intimidad de la mujer: Le gustaría que la pelirroja tuviera el detalle de invitarle a pasar, vaya si le gustaria, pero ella mantiene la puerta entornada y apoya el hombro en la jamba en una actitud relajada y amistosa, pero que no deja lugar a dudas: de ahí no pasa usted, al menos de momento, ${ }^{23}$

\footnotetext{
Ibid. 1, 60 .

${ }^{2}$ Ibid. $1,157-158$.
} 
Finalmente, a consecuencia de un desmayo sufrido por la protagonista, el policía entra en la vivienda quebrando las fronteras de ese espacio en el que se dedica a cuidar de la mujer, sin poder evitar enamorarse de ella al contemplarla en su inconsciencia. Desde ese día Galván y Rosa Bartra intiman, se sientan a la mesa camilla platicando largas horas, tomando café y fumando con parsimonia, a pesar de la imposibilidad para ellos de desarrollar un futuro común. Así se inicia un proceso gradual de confianza en el que comienzan a tutearse y el inspector la visita casi a diario llevándole comida y obsequios, hasta el punto de que los límites antes infranqueables de la casa se difuminan a causa de la fuerza de esa relación en la que los dos personajes comparten con gusto incluso los silencios. De tal manera se rompen đe forma paralela las fronteras personales y las fisicas de la intimidad y la privacidad del hogar: El inspector le habla con las manos hundidas en los bolsillos del pantalón y mirándose los zapatos, muy próximo a ella y con una tensión solícita en los hombros; ninguno de los dos busca los ojos del otro, y, sin embargo, dirias que no hacen otra cosa que mirarse. ${ }^{\star}$

Más adelante, ese proceso se invierte de nuevo desatando la tragedia, pues se provoca que los límites del hogar se vuelvan a cerrar para el policía ya que, a causa de la insistencia de David en vengarse del inspector, la madre decide que no vuelva por allí. Así, el fatídico día en que Galván regresa y aprecia desde la ventana la figura de la pelirroja caída sobre un costado, se encuentra con la puerta, hasta entonces siempre abierta, cerrada ahora con llave. Por esa razón pierde un tiempo valioso mientras rompe el cristal con el fin de saltar al interior para llevar a Rosa Bartra a la clínica de Maternidad, suceso que tendrá consecuencias nefastas. Observamos, por lo tanto, cómo el límite fronterizo de las puertas de la casa, como lugar de tránsito que une y separa, condicionará tanto las interrelaciones de los diversos personajes como su destino.

Según anunciamos previamente, junto a la casa sobresale la significación de otros espacios de carácter, si cabe, más interior e íntimo, como el del propio cuerpo humano. Aunque no debemos olvidar, no obstante, la recurrente imagen de un espacio corporal animal, el de las lagartijas cuyos rabos corta continuamente el adolescente ansioso por comprobar cómo, a pesar de la mutilación, siguen serpenteando en un afán asombroso de supervivencia, de la misma forma que él, a pesar del desengaño, debe seguir luchando por salir adelante frente a las penosas circunstancias que le ha tocado vivir.

Por su parte, el cuerpo humano se presenta como un espacio de gran riqueza narrativa, expresiva y significativa². Gracias a él se logra caracterizar

24/bid. 1, 307.

23 Zumthor (1994: 22) es uno de los estudiosos que ha puesto de manifiesto la complejidad y la riqueza espacial del cuerpo humano. 
a los personajes no sólo externa sino también internamente, pues el espacio corporal es un ámbito que posee grandes paralelismos con los lugares físicos y geográficos, que puede ser descrito y recorrido igual que ellos y que ha constituido en muchos casos un símil estilístico del espacio al tenerse en cuenta como modelo analógico del universo. En la novela de Marsé son muchas las descripciones físicas que se exponen de los diversos personajes como, por ejemplo, cuando se define el rostro del inspector como una mezcla entre ave de rapiña y reptil que no le hace más amenazante sino más atractivo; o cuando, mediante el cuerpo, son caracterizados incluso los propios fantasmas que hablan con David, como el del padre cuyo espacio corporal es perfectamente tangible. No sólo serán los rasgos físicos los que logran definir a los personajes, pues más determinante es, en la línea de las teorias proxémicas, el modo en que los caracteres transmiten su propia percepción del espacio a través de sus gestos, actitudes o movimientos, delatando sus intenciones o estados de ánimo. Así se refleja al mostrar con la adusta cara del inspector la gran paciencia que éste posee ante las barbaridades que exclama David; $o$ al ser comparada la mansedumbre de su paso con el del perro, como si ambos estuvieran unidos en su penosa marcha. Un ejemplo mús destacado es el que se recrea en el pasaje que revela la simbólica posición del inspector frente a la casa de la pelirroja, propiciando una representación del espacio que nace del propio ámbito corporal: ... parecía tan acostumbrado a perma. necer asi de pie, tan quieto y con los hombros un poco encogidos y tan ajeno al trasiego de la vida en tomo, a la llovizna gris o al sol implacable, que a menudo parecía alguien llegado de fuera que se hubiera extraviado en el barrio, y que no le importara su extravio ni tuviera prisa por orientarse ni por nada. Su figura alta y de movimientos sinuosos, como retardados, sugería una malformación que en realidad no tenia, una suerte de flexión muscular o de encantamiento, una disposición fisica a la inmovilidad. ${ }^{25}$

Pero, aunque todos los personajes desnuden en parte su interior a través de la imagen de su cuerpo, es David el que mayor simbolismo desarrolla en esta línea. El muchacho resalta por el desengaño ante el mundo y por la lucha contra la fragilidad de la apariencia de verdad y la confusión entre el bien y el mal. Proyectada esta problemática en su espacio corporal, la ambigüedad sexual que lo caracteriza se atisba ya en las muchas ocasiones en las que se viste de niña en su habitación. De ahí las dudas sobre su sexualidad y el reconocimiento de no corresponderse con su propio cuerpo, proceso acrecentado por las visitas que realiza a su abuela en el asilo en las que decide vestirse de chica, ya que con su imagen habitual de nin̄o es ignorado por la anciana

"Ibid. 1, 30-31. 
como si en realidad no existiera: Ella nunca le hace caso. No parece verle ni ofrle, sus ojos de agua le traspasan el pecho. Parado ante esa mirada que no le alcanza, David no se siente nada bien dentro de su cuerpo, y ésa podría ser quizás la primera vez que tuvo conciencia de ese malestar. ${ }^{27}$

Además de ese desajuste entre espacio corporal y espacio mental, el personaje entra en un nuevo conflicto provocado en este caso por una parte concreta de su anatomía, los oídos. Ciertamente, esa zona es un elemento clave desde el comienzo de la narración, pues no debemos olvidar que la casa se sitúa en un antiguo consultorio de otorrino en el que todavía permanece la imagen de una gran oreja colgada en la pared. Los oídos de David condicionarán, por lo tanto, la historia narrada, al experimentar una extraña enfermedad que genera insoportables ruidos en la conciencia, de modo que el joven afirma insistentemente tener un bosque de jilgueros en la mente; $A$ ratos es como si rasgaran una seda dentro de mis orejas, a como hace una ola cuando se retira suavemente de la arena y vuelve al mar. O el zumbido de un ventilador. Ahora ya conozco todos los ruidos. Y luego tiempo después un dia se me metió un grillo en cada oreja, o mejor, un enjambre de abejas. Hay dias que tengo una pajarería en el coco, doctor. Eso en el mejor de los casos, cuando esa puñeta se hace más o menos soportable, porque a veces se produce bruscamente un cambio, una subida de tono, llega de forma imprevisible y entonces lo que tengo en la cabeza es un estruendo, una pesadilla. ${ }^{2 B}$

Por las noches, en el espacio de la oscuridad más propenso que el del día al silencio, los ruidos se multiplican en los ofdos del muchacho atormentando su existencia con brusquedad. Tan sólo, en ocasiones, el zumbido del Spitfire, el avión accidentado del piloto de la revista que David tiene en su cuarto, consigue calmar como un bálsamo los demás sonidos. Así, esa capacidad auditiva, que incluso le permite hablar con los muertos y personas que no existen condicionando la organización de la trama, sólo cesará en el momento de su muerte de una forma que premonitoriamente le había diagnosticado tiempo atrás el fantasma del otorrino: Porque ya para siempre, hasta que te mueras y el plomo de la nada se funda en tus oidos y te regale una eternidad de silencio, esos ruidos irán contigo y perforarán tus dias y tus noches como los gusanos barrenan la tierra bajo el verde césped. Habras de defenderte con uñas y dientes, muchacho. Recuérdalo siempre que mires mi oreja colgada en esta pared..$^{24}$

Sin embargo, existe un nivel de intimidad espacial mucho más profundo, ya que si resaltan las connotaciones del cuerpo humano en su conjunto o las

\footnotetext{
I lbid. 1,97 .

lbid. 1, 103.

Ibid. $1,104$.
} 
đe la zona de los oídos, no menos relevante es el ámbito interior del útero materno. Este espacio se recrea como un lugar paralelo y similar en su significado al del hogar natal, pues en él se experimenta la protección propia del marco original. A través de la simbología del útero la pelirroja le expone al inspector cómo el carácter de David no se puede definir como mentiroso sino como fantasioso, provocado por las circunstancias que le han hecho crecer deprisa y en soledad por la ausencia de la figura paterna. Ella sostiene la veracidad de esta aseveración mediante el hecho de que esos aspectos le fueron manifestados ya en el propio útero, lugar concebido por el chico como un refugio ante la hostilidad del medio exterior: Tiene fe en algunas cosas importantes. Pero es bastante nervioso e inestable, lo admito. Un chico especial. Ya lo era antes de nacer. Su padre no lo queria, ¿sabe?, andaba por aquel entonces con otras querencias, y quizá por eso yo sentía el niño dentro de mi como... como una cosa escondida. Lo sentía como si quisiera ocultarse. ${ }^{30}$

Aunque la mayor simbología de ese espacio se refleja en las palabras del propio narrador, que ha percibido todos los acontecimientos que relata desde el útero de la protagonista, siendo un feto de pocos meses que, no obstante, recuerda todo como en "un sueño congelado en la placenta de la memoria" (p.9). Asi, ese ámbito se erige en la trama como un lugar privilegiado, donde la madre le protege del exterior simplemente poniendo la mano sobre la barriga, desde donde puede contemplar o, al menos imaginar, todo lo que sucede: Hace apenas un minuto todavfa flotaba enroscado en el vientre materno, pero ya mis ojos, desde esa tiniebla esponjosa, presentian la luz del mundo y sus reiterados espejismos: lo que veo y lo que no veo son la misma cosa." De tal manera, el pequeño narrador percibe, todavía en posición fetal y con los puños en las cuencas de los ojos, el ambiente de los trastornos familiares y las emociones amargas experimentadas en la casa. De igual modo que reconstruye las confidencias y los actos del hermano mayor que le habla a menudo cuando Rosa no se da cuenta y que incluso minimiza sus opiniones llamándole microbio, gusano peludo que envenena la sangre de la madre o boniato nadando en una pecera. En este contexto, a pesar de las penurias y de la fragilidad de su existencia, el feto alcanza en el útero un hogar en forma de cálida burbuja en el que, sin embargo, no sentirá la soledad del espacio-concha aislado ante el exterior ${ }^{32}$. ... recibo a través del cordón umbilical el coletazo alegre de su indomable voluntad de vivir, de superar penas y añagazas y desdenes vengan de donde vengan, fortaleciendo día tras día su firme propósito de no dejarse vencer por la soledad y el miedo, la enfermedad y $\mathrm{tn}$ embarazo no deseado, la pobreza y el desamor y lo que el destino le depare.

\footnotetext{
${ }^{30}$ Ibid. 1, 164.

"Ibid. 1, 15-16.

${ }^{32}$ A este respecto véase el estudio de Bachelard 1965: 140-170.
} 
Juraria que esa tarde, si hubiese podido, al salir para que la viera el médico, de buena gana me habria dejado en casa. Pero cómo saberlo. Yo eslaba por aquel entonces balanceándome al borde de la vida y a un paso de la muerte, de espaldas al mundo y seguramente cabeza abajo. El renacuajo ya presentia la vida en torno, pero solamente como zarpazos de luz..3.

Pero la protección y la seguridad de ese espacio no es máxima, ya que el narrador percibe también las dolencias de la madre que le afectan a él mismo al ser su vínculo enorme e indisoluble. Aprecia, pues, las punzadas, los vahídos, los cambios de ritmo en la respiración, los desmayos y su temor a un desprendimiento del vientre grávido. Así, a la hora del trágico parto el narrador perderá ese refugio hogareño del útero, a la vez que queda huérfano lamentando que la pelirroja no se lo haya llevado con ella, puesto que se resentirá no sólo físicamente sino también psíquicamente: He nacido prematuro, azul de cianosis y pesando menos que un mosquito, con una lesión cerebral que me tendrú postrado no sé cuántos años y una pinta de niño lobo que tira de espaldas. Durante tres meses, mis tiemas zarpas crecerán entre algodones. ${ }^{\text {bi }}$

En suma, a través de los desplazamientos realizados por el narrador desde el útero hacia la casa y al barranco exterior y viceversa, apreciamos la historia de una familia rota en la Cataluña de la posguerra, cuyo significado existencial está profundamente ligado a los simbólicos espacios en los que acontece su vida, unos ámbitos que no se limitan a ser un soporte ubicador de los hechos sino que se convierten en un protagonista mis de la excelente novela que Juan Marsé nos brinda en el nuevo milenio.

\section{REFERENCIAS BIBLIOGRÁFICAS}

- Albaladejo, Tomás. 1992. Semántica de la narración: la ficción realista. Madrid: Taurus.

- Bachelard, Gaston. 1965. La poética del espacio. México: Breviarios. Fondo de Cultura Económica.

- Camarero, Jesús. 1994. "Escritura, espacio, arquitectura: una tipología del espacio literario", Signa 3, pp.89-101.

- Garrido Domínguez, Antonio. 1993. El texto narrativo. Madrid: Síntesis.

- 1997. Teorías de la ficción literaria. Madrid: Arco Libros.

- Goodman, Nelson. 1990. Maneras de hacer mundos. Madrid: Visor.

- Marsé, Juan. 2000. Rabos de lagartija. Barcelona: Areté.

\footnotetext{
${ }^{31}$ lbid. 1, 67-68.

${ }^{4}$ Ibid. 1, 342 .
} 
- Valles Calatrava, José Ramón. 1999. El espacio en la novela. El papel del espacio narrativo en La ciudad de los prodigios de Eduardo Mendoza. Almeria: Universidad.

- Wellek, René y Warren, Austen. 1948. Teoría literaria. Madrid: Gredos.

-Zumthor, Paul. 1994. La medida del mundo. Representación del espacio en la E.M. Madrid: Cátedra. 